18 Haw WW, Manche EE. Effect of preoperative pupil measurements on glare, halos, and visual function after photoastigmatic refractive keratectomy. J Cataract Refract Surg 2001;27:907-16.

19 Lee YC, Hu FR, Wang IJ. Quality of vision after laser in situ keratomileusis: influence of dioptric correction and pupil size on visual function. J Cataract Refract Surg 2003;29:769-77.

20 Jimenez JR, Villa C, Anera RG, et al. Binocular visual performance after LASIK. $J$ Refract Surg 2006;22:679-88.

21 Applegate RA. Glenn Fry award lecture 2002: wavefront sensing, ideal corrections, and visual performance. Optom Vis Sci 2004;81:167-77.
22 Anera RG, Jimenez JR, Jimenez dB, et al. Changes in corneal asphericity after laser in situ keratomileusis. J Cataract Refract Surg 2003;29:762-8.

23 Jimenez JR, Anera RG, Jimenez dB. Equation for corneal asphericity after corneal refractive surgery. J Refract Surg 2003;19:65-9.

24 Jimenez JR, Anera RG, Diaz JA, et al. Corneal asphericity after refractive surgery when the Munnerlyn formula is applied. J Opt Soc Am A Opt Image Sci Vis 2004;21:98-103.

25 Gatinel D, Malet J, Hoang-Xuan T, et al. Analysis of customized corneal ablations: theoretical limitations of increasing negative asphericity. Invest Ophthalmol Vis Sci 2002;43:941-8.

\title{
VIDEO REPORT
}

\section{Pigmented free-floating iris cysts}

Gurdeep Singh, Kalpana Narendran, Department of Pediatric Ophthalmology, Aravind Eye Hospital and Post Graduate Institute of Ophthalmology, Tamil Nadu, India

Veerappan R Saravanan, V Narendran, Retina and vitreous services, Aravind Eye Hospital and Post Graduate Institute of Ophthalmology, Tamil Nadu, India

\section{ABSTRACT}

Free-floating iris cysts are rare. These cysts may be located in the vitreous or the anterior chamber. Anterior chamber cysts can be idiopathic or induced by trauma or surgery. Vitreous cysts may be associated with the remnants of the hyaloid system and therefore be congenital, or can result from trauma or ocular disease.

Case 1: An 8-year-old girl presented for routine follow-up with a past history of undergoing traumatic cataract extraction with intraocular lens implantation OD one year prior. Slit lamp examination showed a free floating dark brown, pigmented round iris cyst in the anterior chamber OD.

Case 2: A 9-year-old boy presented for routine eye examination. Examination of the anterior vitreous showed a large pigmented cystic lesion. It was free floating and appeared to be composed of pigmented cells joined together by a semi-translucent membrane, probably composed of pigmentary epithelium.

Discussion: Free-floating iris cysts in the anterior chamber are rare, and can be congenital or associated with trauma, surgery, medications or tumors. The wall usually comprises iris pigment epithelium containing pigment granules. The cysts can get detached from the iris surface and float freely in the anterior chamber, or can get reattached to the iris at some other location. They can remain stable or can grow and cause visual disturbance or secondary glaucoma. Visually symptomatic cysts or cysts causing glaucoma need to be removed surgically or collapsed using NdYAG laser.

The origin of vitreous cysts has been the source of controversy. It has been proposed that they may be associated with the remnants of the hyaloid system and therefore are congenital, or they can result from trauma, retinal surgery or other ocular disease. Bilateral cases have been reported in patients with retinitis pigmentosa. Rarely, vitreous cysts can lead to visual disturbances if they are imposed on the visual axis. Orellana and colleagues removed a vitreous cyst via a pars plana approach, aspirating it with a 20-gauge needle. Awan suggested disrupting the cyst with argon laser photocystotomy as a simpler and safer method.

In our series the patient with the anterior chamber cyst was followed up for a period of two years and the patient with vitreous cyst was followed up for a period of three years without any increase in the size of the cysts or the occurrence of complications.

Correspondence to: Correspondence:Dr Gurdeep Singh, Department of Pediatric Ophthalmology, Aravind Eye Care System, Aravind Eye Hospital and Post Graduate Institute of Ophthalmology, Avinashi Road, Coimbatore641014 , Tamilnadu, India; email: gurdeep9999@yahoo.co.in

To view the full report and accompanying video please go to: http://bj.bmj.com/cgi/content/ full/91/8/1037/DCl

All videos from the $\mathbf{B J O}$ video report collection are available from http://bjo.bmj.com/video/ collection.dtl 